\title{
Desenvolvimento de Látices Nitrílicos Carboxilados
}

\author{
Ana Luzia 0. Macedo \\ Nitriflex S.A. Indústria e Comércio \\ Fernanda M. B. Coutinho \\ Instituto de Química, UERJ
}

Resumo: É apresentando um estudo sobre o desenvolvimento de um processo de polimerização em emulsão de acrilonitrila, butadieno e ácido carboxílico, em escala piloto. O objetivo desse estudo é a produção de látex nitrílico carboxilado com alto teor de sólidos diretamente no processo de polimerização, sem a necessidade de etapas pós-reação de concentração. Foi estudado o efeito da temperatura, do tipo e quantidade de emulsificante, do tipo e quantidade de iniciador, do tipo de agitador e da velocidade de agitação e das etapas de adição incremental. Para isso, foram realizadas 32 reações, das quais somente 7 chegaram ao alvo de teor de sólidos desejado (50\%). Os látices obtidos foram caracterizados quanto ao seu teor de sólidos, tamanho e distribuição de tamanhos das partículas, e por espectroscopia na região do infravermelho para determinação da composição monomérica. Foram obtidos látices com até $57 \%$ de sólidos totais. O tamanho médio de partícula variou de 130 a $230 \mathrm{~nm}$.

Palavras-chave: Polimerização em emulsão, látex, determinação de tamanho de partícula, alto teor de sólidos.

\section{Development of Carboxylated Nitrile Latices}

Abstract: An emulsion polymerization process of acrylonitrile, butadiene and carboxylic acid was studied, in a pilot plant, for producing carboxylated nitrile latices with high solids content directly from the polymerization process, without the need of post-reaction steps of concentration. The effect of temperature, type and amount of emulsifier, type and amount of initiator, type of stirring system, stirring speed and incremental additions for producing high solid latices was studied. To attain this goal, 32 polymerization reactions were carried out, but only 7 attained the target for total solids (50\%). The solids content, the average particle size and its distribution and the monomer composition were determined. A latex containing up to $57 \%$ of total solids was obtained. The average particle size ranged from 130 to $230 \mathrm{~nm}$.

Keywords: Emulsion polymerization, latex, particle size determination, high solids content.

\section{Introdução}

Látices nitrílicos carboxilados são dispersões coloidais de partículas poliméricas obtidas através de polimerização em emulsão de acrilonitrila, butadieno e ácidos carboxílicos ${ }^{[1,2,4,13,15]}$.

São classificados de acordo com o seu teor de acrilonitrila em baixo (10-25\%), médio (25-35\%) e alto teor (35 a 50\%). A resistência do látex nitrílico a óleo aumenta com o teor de acrilonitrila. Esse tipo de material possui uma boa resistência ao calor e, se devidamente protegido por antioxidantes, é resistente à degradação oxidativa ${ }^{[1]}$. A temperatura de transição vítrea $(\mathrm{Tg})$ aumenta rapidamente e quase linearmente com o teor de acrilonitrila, bem como a histerese e a deformação permanente, enquanto que a resiliência diminui.

Os látices nitrílicos são utilizados em muitas aplicações tais como: artigos de imersão resistentes a óleos e solventes apolares (ex.: mangueiras, gaxetas, válvulas); luvas; revestimentos de superfície; aglomerados para celulose e fibras em geral; adesivos; impregnação de tapetes com resistência a derivados de petróleo; selantes que contenham óleos e aerossóis; têxteis (não-tecidos) e nas indústrias de papel e couro ${ }^{[3,5,7]}$.

Este trabalho trata de um estudo sobre o desenvolvimento de látex nitrílico carboxilado com alto teor de sólidos e baixa viscosidade através de processo de polimerização em emulsão.

Não é econômico submeter látices poliméricos a técnicas convencionais de concentração, tais como evaporação, cremagem e centrifugação, para a obtenção de látices com teor de sólidos acima de 55\%[6,8-12,14,16,17-20]. Esses látices tendem a apresentar viscosidade elevada, o que representa um obstáculo na aplicação desses materiais em composições de revestimento de superfícies e adesivos, que necessitam de uma composição de látex suficientemente fluida e estável para permitir a sua aplicação como um filme fino. Sendo assim, este trabalho poderá contribuir para o desenvolvimento de uma tecnologia adequada para a produção mais econômica desse tipo de látex.

Neste estudo foi avaliado o efeito da temperatura, do tipo e quantidade de emulsificante, do tipo e quantidade de iniciador, do tipo de agitador e da velocidade de agitação e das

Autor para correspondência: Fernanda M. B. Coutinho, Instituto de Química, Departamento de Processos Químicos, UERJ, Av. Maracanã 524, Pavilhão Haroldo Lisboa da Cunha, CEP: 20559-900, Rio de Janeiro, RJ, Brasil. E-mail: fmbc@uerj.br 
etapas de adição incremental para obtenção de um látex com alto teor de sólidos. Foi estudada ainda a influência dessas variáveis sobre o tamanho médio de partícula e o tipo de distribuição, pois se espera obter um maior grau de empacotamento das partículas com uma distribuição bimodal ou polimodal, com o conseqüente aumento do teor de sólidos da emulsão.

\section{Experimental}

\section{Reagentes}

Os monômeros usados foram: acrilonitrila da Acrinor, 1,3-butadieno da Petroquímica União, usado após remoção do inibidor por lavagem com solução de hidróxido de sódio, e ácido metacrílico da Degussa. Todos os monômeros foram cedidos pela Nitriflex S.A. Outros componentes usados foram: água desmineralizada, surfactantes aniônicos (lauril éter sulfato de sódio e lauril sulfato de sódio da Cognis, dodecilfenoxibenzeno dissulfonato de sódio da Dow Química), surfactante não-iônico (mistura de álcoois graxos etoxilados da Cognis), eletrólito (fosfato trissódico dodeca-hidratado da Fosmix), iniciador gerador de radicais livres por decomposição térmica (persulfato de potássio da Degussa-fabricante Peroxid Chemie $\mathrm{GmbH}$ ) e por meio de reação redox (constituído por hidroperóxido de cumila da Rhodia Brasil, sulfato ferroso da Resitec-Shanco International e formaldeído sulfoxilato de sódio da Basf), agente de transferência de cadeia (dodecilmercaptan da Arkema Química), antioxidante (amínico e fenólico da Ciba Especialidades Químicas) e biocida (derivado de triazina da Miracema Nuodex).

\section{Equipamentos}

Além dos equipamentos e vidrarias tradicionais usados em laboratório, foram utilizados os seguintes aparelhos: viscosímetro Brookfield, modelo RVT ${ }^{1}$, tensiômetro Lauda, modelo LD ${ }^{1}$, Estufa de Microondas, modelo Labwave 9000, marca $\mathrm{CEM}^{1}$, estufa com circulação forçada de ar, marca $\mathrm{CEM}^{1}$, equipamento para medição de tamanho médio de partícula e distribuição de tamanhos Zetasizer 3000HS, Malvern Instruments Ltd. ${ }^{2}$, espectrômetro de infravermelho com transformada de Fourier (FTIR), modelo System 2000, Perkin-Elmer ${ }^{1}$ e unidade de polimerização - Planta-Piloto ${ }^{1}$.

\section{Processo de polimerização}

As reações de polimerização foram realizadas em um reator de aço inoxidável de $50 \mathrm{~L}$ de capacidade, com camisa para aquecimento ou resfriamento com água. $\mathrm{O}$ reator possui impelidor para promover a agitação do meio reacional, indicador de velocidade e de pressão e controlador de temperatura. O processo de síntese consistiu da adição ao reator de polimerização de emulsificante, monômeros, iniciador e agente de transferência de cadeia. Foi avaliado o efeito da adição incremental, temperatura, tipo e quantidade de inicia-

\footnotetext{
${ }^{1}$ Nitriflex S.A. Indústria e Comércio, Duque de Caxias - Rio de Janeiro/RJ.
}

${ }^{2}$ Instituto de Macromoléculas Professora Eloísa Mano (IMA), Rio de Janeiro/RJ.
Tabela 1. Formulação básica de polimerização.

\begin{tabular}{lc}
\hline \multicolumn{1}{c}{ Componentes } & pcm \\
\hline Água & 70 \\
Lauril éter sulfato de sódio & 0,7 a 2 \\
Mistura de álcoois graxos etoxilados & 0 a 5 \\
Dodecilfenoxibenzeno dissulfonato de sódio & 2 \\
Fosfato trissódico dodeca-hidratado & 0,11 \\
\hline \multicolumn{2}{c}{ Monômeros } \\
\hline Acrilonitrila & 30 \\
1,3-Butadieno & 65 \\
Ácido metacrílico & 5 \\
Dodecilmercaptan & 1,07 \\
\hline \multicolumn{2}{c}{ Iniciador térmico } \\
\hline Persulfato de potássio & 0,015 \\
\hline \multicolumn{2}{c}{ Iniciador redox } \\
Hidroperóxido de cumila \\
Fulfato ferroso $\quad 0,02$ \\
\hline
\end{tabular}

dor, tipo e quantidade de emulsificante e tipo de impelidor. A cada entrada de reagente, o reator era purgado com nitrogênio para garantir a ausência de oxigênio na atmosfera reacional. O acompanhamento da conversão de monômeros em polímeros foi feito através de determinação do teor de sólidos (por gravimetria) a cada duas horas de reação.

Para todas as reações foi adotado um mesmo teor de acrilonitrila (30 pcm), 1,3-butadieno (65 pcm) e ácido metacrílico $(5 \mathrm{pcm})$. Somente foi variada a forma de adição, ou seja, carga total no início ou em diferentes formas incrementais. $\mathrm{O}$ teor de água considerado foi de $70 \mathrm{pcm}$, bem abaixo do teor normalmente usado nas reações de polimerização convencionais $(180 \mathrm{pcm})$. Esse valor foi adotado para se tentar obter um teor de sólidos de 58\% (Tabela 1).

\section{Resultados e Discussão}

\section{Influência da temperatura sobre o perfil cinético de polimerização}

Inicialmente foi realizada a avaliação do perfil cinético da reação a 50 e $43{ }^{\circ} \mathrm{C}$ (Figura 1), adotando a adição de 33,3\% dos monômeros no início da reação.

A $43{ }^{\circ} \mathrm{C}$ não houve registro de disparo de temperatura em nenhum momento da reação. A $50{ }^{\circ} \mathrm{C}$ houve disparo na $1^{a}$ hora de reação até $62^{\circ} \mathrm{C}$. Como as reações ficaram muito lentas, foram interrompidas antes de se realizar as adições incrementais dos monômeros.

\section{Influência da temperatura de reação associada à forma de adição dos monômeros e do modificador de cadeia sobre 0 perfil cinético de polimerização.}

Foi feita a avaliação do perfil cinético da reação a 50 e a $43{ }^{\circ} \mathrm{C}$ (Figura 2), adotando a adição de $60 \%$ dos 


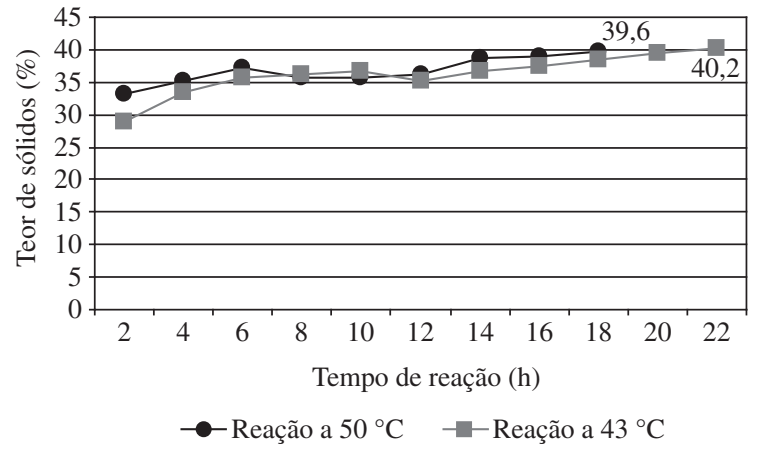

Tipo de emulsificante

Lauril éter sulfato de sódio/mistura de álcoois graxos etoxilados

Tipo de iniciador

Térmico

Tipo de impelidor

FBT

Figura 1. Variação do teor de sólidos com o tempo de polimerização a $50{ }^{\circ} \mathrm{C}$ e a $43{ }^{\circ} \mathrm{C}$ (adição de 33,3\% dos monômeros no início da reação).

monômeros e do modificador de cadeia no início da reação, $30 \%$ na $1^{\mathrm{a}}$ alíquota incremental e $10 \%$ na $2^{\mathrm{a}}$.

Em ambas as reações, apesar do melhor controle de temperatura, foi observada a formação de coágulos, o que impediu a conversão completa e a obtenção do teor de sólidos desejado.

\section{Influência da adição incremental de emulsificante associada às adições incrementais dos monômeros sobre o perfil cinético de polimerização.}

Foi feita a avaliação do perfil cinético da reação a $43{ }^{\circ} \mathrm{C}$ (Figura 3), adotando a adição de $60 \%$ dos monômeros e do modificador de cadeia no início da reação e invertendo a ordem das adições incrementais, ou seja, $10 \%$ na $1^{\mathrm{a}}$ alíquota e $30 \%$ na $2^{\mathrm{a}}$.

Em uma das reações, as alíquotas incrementais de emulsificante aniônico foram adicionadas junto com os monômeros e na outra as alíquotas só foram adicionadas quando ocorria

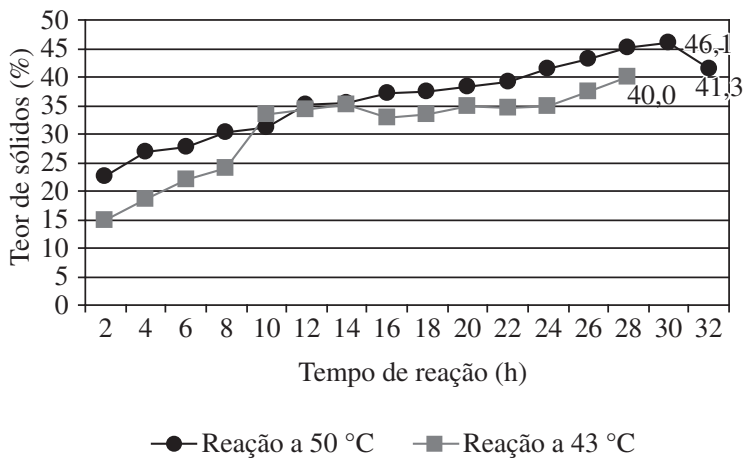

Tipo de emulsificante

Lauril éter sulfato de sódio/mistura de álcoois graxos etoxilados

Tipo de iniciador

Térmico

Tipo de impelidor

FBT

Figura 2. Variação do teor de sólidos com o tempo de polimerização a $50{ }^{\circ} \mathrm{C}$ e a $43{ }^{\circ} \mathrm{C}$ (adição de $60 \%$ dos monômeros no início da reação).

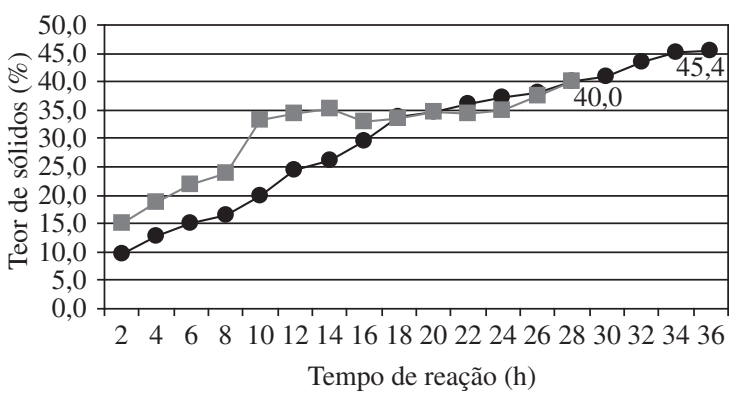

Adição de emulsificante incremental junto com os monômeros

Adição de emulsificante incremental após diminuição da velocidade de conversão

$\begin{array}{cc}\text { Tipo de emulsificante } & \begin{array}{r}\text { Lauril éter sulfato de sódio/mistura } \\ \text { de álcoois graxos etoxilados }\end{array} \\ \text { Tipo de iniciador } & \text { Térmico } \\ \text { Tipo de impelidor } & \text { FBT }\end{array}$

Figura 3. Variação do teor de sólidos com o tempo de polimerização a $43{ }^{\circ} \mathrm{C}$ em função do modo de adição do emulsificante aniônico nas alíquotas incrementais.

diminuição na velocidade de conversão dos monômeros (diferença no teor de sólidos abaixo de 1\%) (Figura 3).

Na polimerização onde a alíquota incremental de emulsificante foi adicionada após a diminuição da conversão houve uma sensível melhora na cinética da polimerização, sem registro de formação de coágulos. O tempo reacional foi longo (36 h) e o teor de sólidos estabilizou em torno de $45,4 \%$ (abaixo do alvo de 58\%).

\section{Influência do teor de iniciador sobre o perfil cinético de polimerização}

Com o objetivo de reduzir o tempo reacional, foi feita uma reação, com base na anterior, aumentando o teor de iniciador total de $0,01 \mathrm{pcm}$ para $0,02 \mathrm{pcm}$ (Figura 4).

A reação onde se utilizou a maior concentração de iniciador foi a melhor conseguida até então. Chegou-se a um teor de sólidos de 50,6\%. Porém, o tempo de reação foi muito longo (52 h), mesmo com ligeiros aumentos de temperatura em determinados tempos da reação (a partir da $12^{\mathrm{a}}$ hora $-\mathrm{T}=46^{\circ} \mathrm{C}$; a partir da $33^{\mathrm{a}}$ hora $-\mathrm{T}=48{ }^{\circ} \mathrm{C}$; a partir da $40^{\mathrm{a}}$ hora $-\mathrm{T}=52{ }^{\circ} \mathrm{C}$; a partir da $44^{\mathrm{a}}$ hora $-\mathrm{T}=55^{\circ} \mathrm{C}$ e a partir da $48^{\mathrm{a}}$ hora $-\mathrm{T}=60^{\circ} \mathrm{C}$ ). Não se verificou a instabilização do látex nitrílico carboxilado formado.

\section{Influência do tipo de impelidor usado na agitação do reator sobre o perfil cinético de polimerização}

Neste trabalho foi feito ainda um estudo sobre a influência do tipo de impelidor usado na agitação da massa reacional sobre o perfil cinético da polimerização (Figura 5). A reação com $0,02 \mathrm{pcm}$ de iniciador foi repetida substituindo o impelidor FBT ("flat blade turbine"), usado em todas as reações anteriores, pelo AFT ("axial flow turbine"), que permite uma 


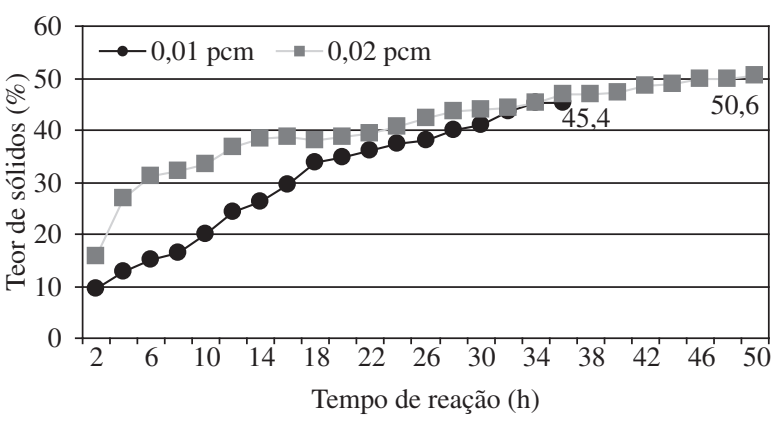

Adição dos monômeros

$60 \%$ no início

Tipo de emulsificante

Lauril éter sulfato de sódio/mistura de álcoois graxos etoxilados

Tipo de iniciador

Térmico

Tipo de impelidor

FBT

Figura 4. Variação do teor de sólidos com o tempo de polimerização em função do teor de iniciador.

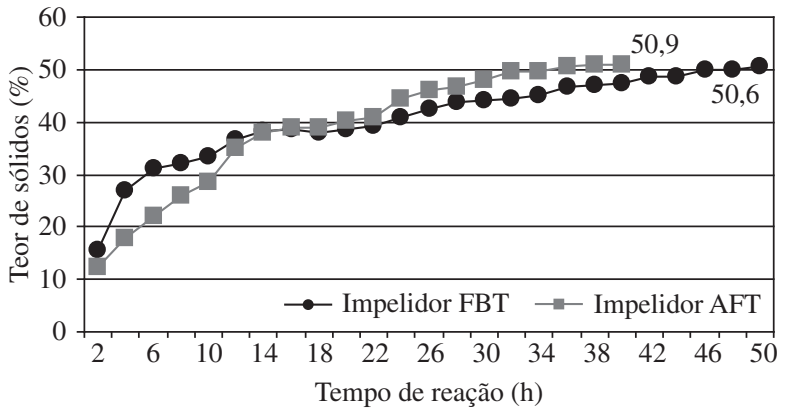

Adição dos monômeros

$60 \%$ no início

Tipo de emulsificante

Lauril éter sulfato de sódio/mistura de álcoois graxos etoxilados

Tipo de iniciador

Térmico

Figura 5. Influência do tipo de impelidor sobre o perfil cinético da polimerização.

melhor homogeneização do meio reacional. Esses dois tipos de impelidores são mostrados na Figura 6.

Quando se trocou o tipo de impelidor houve uma redução acentuada do tempo de reação, de 52 para 40 h. Além disso, a reação com o impelidor AFT apresentou um teor de sólidos final ligeiramente superior $(50,9 \%)$ ao da reação com o impelidor FBT (50,6\%). Em função desse resultado, as demais reações foram conduzidas com o impelidor AFT.

\section{Influência da adição do 1,3-butadieno no início da reação sobre o perfil cinético}

O 1,3-butadieno foi adicionado todo no início da polimerização, a fim de se controlar melhor a variação da pressão. Nessa condição, foram realizadas três reações com diferentes teores de emulsificante aniônico inicial (1;2 e 4 pcm) (Figura 7).

Não houve conversão quando se utilizou 1 pcm de emulsificante, essa quantidade não foi suficiente para gerar mice-

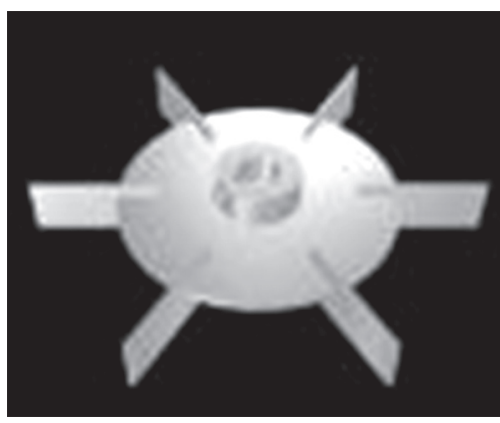

(a)

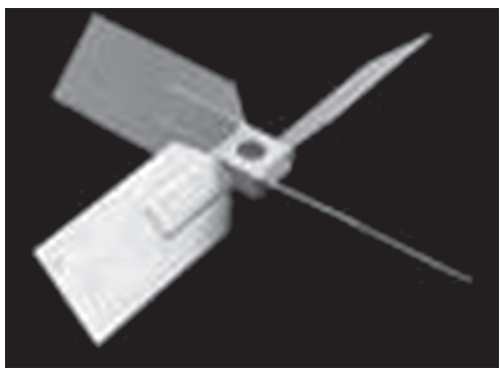

(b)

Figura 6. a) Impelidor tipo FBT; e b) Impelidor tipo AFT.

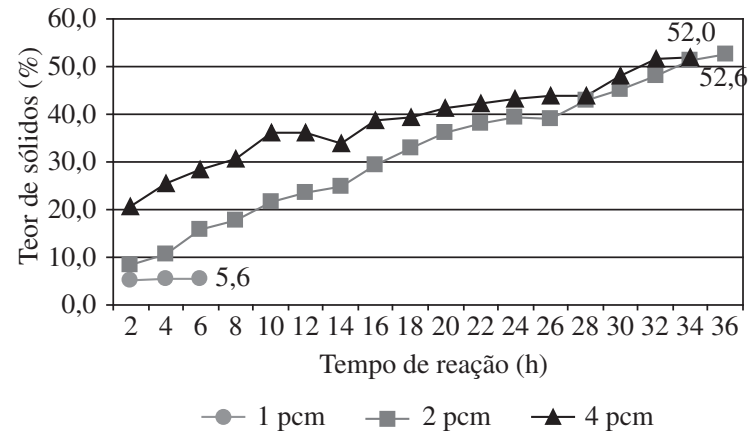

Adição dos monômeros

$60 \%$ no início de acrilonitrila e ácido metacrílico e $100 \%$ de butadieno

Tipo de emulsificante

Lauril éter sulfato de sódio/mistura de álcoois graxos etoxilados

Tipo de iniciador

Térmico

Tipo de impelidor

AFT

Figura 7. Variação do teor de sólidos com o tempo de polimerização - Diferença no perfil cinético em função da quantidade de emulsificante aniônico inicial, mantendo a adição da quantidade total de 1,3-butadieno no início da reação.

las. A adição de 2 pcm de emulsificante levou a uma boa conversão, porém, a viscosidade aumentou. Após a adição da $2^{\mathrm{a}}$ alíquota incremental de emulsificante aniônico, acrilonitrila, ácido metacrílico, modificador de cadeia e iniciador houve um disparo de temperatura, chegando a $49{ }^{\circ} \mathrm{C}$ e esta continuou aumentando até $61,7^{\circ} \mathrm{C}$, mesmo com a água de refrigeração totalmente aberta. Esse comportamento foi atribuído ao aumento da viscosidade, que dificultou a troca térmica durante a reação. Esse aumento de viscosidade ocorreu em função do aumento do número de partículas com o aumento da quan- 
tidade de emulsificante ${ }^{[1,2,4]}$. Foi feita então uma reação com 4 pcm de emulsificante aniônico. A viscosidade da batelada ainda ficou alta, devido ao maior teor de emulsificante inicial, que gerou um número maior de partículas.

\section{Influência do tipo de iniciador: decomposição térmica versus redox}

A reação que havia dado $50,6 \%$ de sólidos foi repetida, substituindo apenas o iniciador de decomposição térmica por um sistema redox (Figura 8).

A Figura 8 mostra que o tempo de polimerização sofreu um decréscimo de 52 para $40 \mathrm{~h}$, somente com a substituição do iniciador. Como a reação com o sistema redox foi muito mais rápida, verificou-se uma reversão da reação (queda de sólidos) a partir da $30^{\mathrm{a}}$ hora. Esse problema foi contornado, elevando a temperatura do meio reacional até $57^{\circ} \mathrm{C}$.

\section{Influência do tipo de emulsificante}

Foi avaliado o efeito do tipo de emulsificante. No lugar do emulsificante não-iônico foi usado um co-surfactante aniônico (dodecilfenoxibenzeno dissulfonato de sódio) (Figura 9).

Apesar de o teor de sólidos da reação realizada com mistura de emulsificantes aniônicos ter sido o mais alto obtido neste estudo, foram observados disparos de temperatura (até $70,5^{\circ} \mathrm{C}$ ), após a adição incremental de iniciador, e a viscosidade do látex ficou alta. Na reação com a mesma mistura, mas sem adição incremental de emulsificante aniônico, o disparo de temperatura foi minimizado, atingindo $55^{\circ} \mathrm{C}$. A temperatura foi mantida nesse patamar até a obtenção do teor de sólidos de 50\%. Mesmo aumentando a temperatura para $60{ }^{\circ} \mathrm{C}$ no final da reação, o teor de sólidos permaneceu constante.

A Tabela 2 apresenta as características das emulsões poliméricas obtidas.

Apesar das dificuldades encontradas no controle de temperatura e pressão nas diversas reações deste estudo, foi possível obter látices com teor de sólidos acima de 50\% em sete

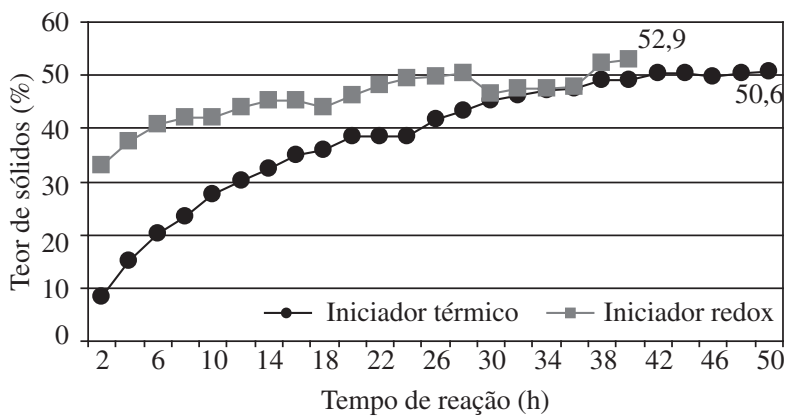

\begin{abstract}
Adição dos monômeros $\quad 60 \%$ no início de acrilonitrila e ácido metacrílico e $100 \%$ de butadieno

Tipo de emulsificante Lauril éter sulfato de sódio/mistura de álcoois graxos etoxilados
\end{abstract}

Tipo de impelidor AFT

Figura 8. Influência do tipo de iniciador sobre o perfil cinético da polimerização.

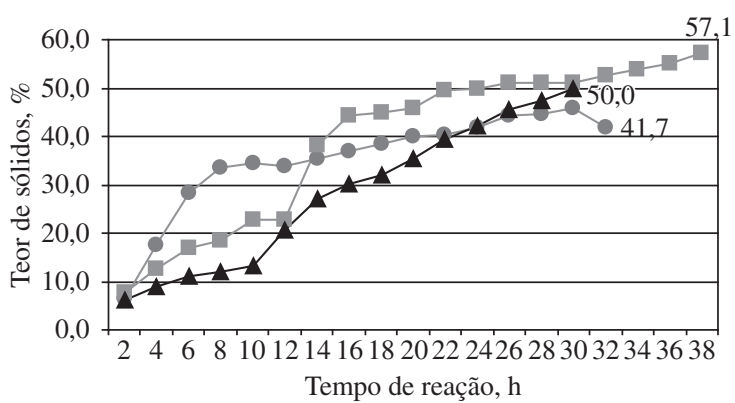

Mistura de emusificante aniônico e nâo iônico com adição incremental de aniônico

Mistura de emulsificantes aniônicos com adição incremental de aniônico

Mistura de emulsificantes aniônicos sem adição incremental de aniônico
Adição dos monômeros

Tipo de emulsificante

Tipo de iniciador

Tipo de impelidor
$60 \%$ no início de acrilonitrila e ácido metacrílico e $100 \%$ de butadieno

Lauril éter sulfato de sódio/mistura de álcoois graxos etoxilados

Térmico

AFT
Figura 9. Efeito do tipo de emulsificante sobre o perfil cinético de polimerização.

reações. Dessas reações, apenas duas apresentaram viscosidade Brookfield elevada (superior a $3.000 \mathrm{cps}$ ). Essa elevação de viscosidade ocorreu devido ao teor mais alto de emulsificante aniônico na carga inicial, que favoreceu a formação de um maior número de partículas de menor diâmetro ${ }^{[1,2,4]}$. Analisando a reação da Figura 8 que foi feita com 4 pcm de emulsificante aniônico no início da reação, verifica-se a formação de uma distribuição bimodal. Porém, os diâmetros médios de ambos os picos foram baixos (22 e $141 \mathrm{~nm}$, respectivamente), o que não foi suficiente para se obter uma maior compactação das partículas sem ocorrer elevação de viscosidade. Na reação das Figuras 3 e 4 cujo teor de sólidos final foi de $45,4 \%$, a bimodalidade apresentou diâmetros com maior tamanho de partícula (176 e $403 \mathrm{~nm}$ ) e, da mesma forma, não ocorreu uma boa compactação, permanecendo o teor de sólidos abaixo do alvo de 50\%. Uma faixa ótima de diâmetros foi conseguida na reação da Figura 9, após a substituição do surfactante não-iônico por um outro tipo de aniônico (68 e $198 \mathrm{~nm})$. Isso favoreceu a formação de um látex com um maior teor de sólidos (57,1 e 54,0\%, antes e após a neutralização, respectivamente).

Para confirmar a incorporação dos monômeros na cadeia polimérica foi determinada a composição monomérica dos látices obtidos em algumas reações, por meio de FTIR. A análise consistiu no preparo de um filme do látex em cristal de Irtran 4. O filme foi seco em placa de aquecimento e submetido à varredura no espectrômetro. A relação entre as bandas 2238, 1698 e $970 \mathrm{~cm}^{-1}$, características das vibrações $\mathrm{C} \equiv \mathrm{N}, \mathrm{C}=\mathrm{O}$ e $\mathrm{C}=\mathrm{C}$, respectivamente, forneceram os per- 
Tabela 2. Resultados de análise do látex nitrílico carboxilado.

\begin{tabular}{|c|c|c|c|c|c|c|c|c|c|}
\hline & \multicolumn{2}{|c|}{ Figura 5} & \multicolumn{2}{|c|}{ Figura 7} & \multicolumn{2}{|c|}{ Figura 8} & \multicolumn{3}{|c|}{ Figura 9} \\
\hline Resultados de análise & FBT & AFT & $2 \mathrm{pcm}$ & $4 \mathrm{pcm}$ & redox & térmico & $\begin{array}{l}\text { Mistura de aniô- } \\
\text { nico e não iônico } \\
\text { com incremental } \\
\text { de aniônico }\end{array}$ & $\begin{array}{c}\text { Mistura de } \\
\text { aniônicos com } \\
\text { incremental de } \\
\text { aniônico } \\
\end{array}$ & $\begin{array}{c}\text { Mistura de } \\
\text { aniônicos sem } \\
\text { incremental de } \\
\text { aniônico } \\
\end{array}$ \\
\hline $\begin{array}{l}\text { Sólidos totais }(\%) \\
\text { (antes da neutralização) }\end{array}$ & 51,2 & 54,2 & 51,2 & 50,5 & 53,1 & 51,4 & 47,9 & nd & 48,3 \\
\hline $\begin{array}{l}\text { Sólidos totais }(\%) \\
\text { (após a neutralização) }\end{array}$ & 50,7 & 52,2 & nd & nd & 50,9 & 50,2 & 47,7 & 54,0 & 46,3 \\
\hline $\begin{array}{l}\text { Viscosidade Brookfield (cps) } \\
\text { (antes da neutralização) }\end{array}$ & 257 & 736 & 13.100 & 3.175 & 50 & 23 & 43,5 & nd & nd \\
\hline $\begin{array}{l}\text { Viscosidade Brookfield (cps) } \\
\text { (após a neutralização) }\end{array}$ & 70 & 122 & nd & nd & 47 & 23 & 37,5 & 620 & 120 \\
\hline $\begin{array}{l}\text { Tamanho médio de } \\
\text { partícula }(\mathrm{nm})\end{array}$ & 218 & 197 & 133 & $22 / 141$ & 204 & 255 & 212 & $68 / 198$ & 124 \\
\hline $\begin{array}{l}\text { Teor de acrilonitrila } \\
\text { combinada }(\%)\end{array}$ & 30,7 & 30,8 & 30,0 & nd & nd & nd & nd & nd & nd \\
\hline $\begin{array}{l}\text { Teor de butadieno } \\
\text { combinado }(\%)\end{array}$ & 63,8 & 63,8 & 63,9 & nd & nd & nd & nd & nd & nd \\
\hline $\begin{array}{l}\text { Teor de ácido metacrílico } \\
\text { combinado }(\%)\end{array}$ & 5,2 & 5,3 & 6,1 & nd & nd & nd & nd & nd & nd \\
\hline
\end{tabular}

nd: não determinado.

centuais de acrilonitrila, butadieno e ácido metacrílico. $\mathrm{Na}$ Tabela 2, pode-se observar que os valores encontrados apresentaram-se bem homogêneos, confirmando a incorporação dos monômeros.

A queda no teor de sólidos totais, observada após a neutralização em todas as reações, foi devida à incorporação de água junto com o hidróxido de amônio usado nessa etapa.

Valores mais elevados de tensão superficial foram obtidos a partir da reação representada na Figura 9, quando o surfactante não-iônico foi substituído por um outro surfactante aniônico.

\section{Conclusões}

Com o estudo realizado, pode-se concluir que é viável a produção de látices nitrílicos carboxilados com alto teor de sólidos. A faixa de temperatura de reação ideal ficou entre 43 e $45^{\circ} \mathrm{C}$. Acima dessa faixa, o controle da pressão é difícil. $\mathrm{O}$ aumento da velocidade de conversão a partir de uma determinada faixa de teor de sólidos (em torno de 30\%) só foi possível com incrementos de temperatura durante a reação. A forma de adição dos monômeros, emulsificante, iniciador e modificador de cadeia que apresentou os melhores resultados foi $60 \%$ no início, $10 \%$ na $1^{\mathrm{a}}$ alíquota incremental e $30 \%$ na $2^{\mathrm{a}}$. As alíquotas incrementais de emulsificante somente devem ser adicionadas após a redução na velocidade de conversão (teor de sólidos inferior a $1 \%$ em 2 h de reação). O tipo de impelidor AFT possibilitou um menor tempo reacional que o tipo FBT e atingiu a mesma faixa de teor de sólidos. Não foi possível atingir o valor máximo de conversão (100\%), o que representaria um teor de sólidos de $58 \%$. Porém, a reação da Figura 9, com a substituição do surfac- tante não-iônico por um co-surfactante aniônico, foi a que atingiu a conversão mais alta $(57,1 \%$ de teor de sólidos $)$. Um teor mais alto de emulsificante aniônico no início da reação foi o responsável pelo aumento da viscosidade do meio reacional observado na reação da Figura 7 (2 pcm) e na reação da Figura 8 (4 pcm). Apesar do maior teor de emulsificante nesta última, a viscosidade foi mais baixa devido à diferença no perfil cinético e à distribuição de tamanhos de partícula. Na reação da Figura 7, a distribuição foi monomodal e na reação da Figura 8 foi bimodal.

\section{Agradecimentos}

Nitriflex S.A. Indústria e Comércio, e ao CNPq.

\section{Referências Bibliográficas}

1. Billmeyer, F. W. - “Tex tbook of polymer science”, John Wiley, New York (1984).

2. Blackley, D. C. - "Polymer latices: science and technology”, Chapman \& Hall, London (1997).

3. Blackley, D. C. - "High polymer latices: their science and technology”, Maclaren \& Sons, London (1966).

4. Blackley, D. C. - "Emulsion polymerization: theory and practice”, Applied Science, London (1975).

5. Budenberg, E. R. - “Introdução à tecnologia do látex”, S A Assessoria Empresarial, São Paulo (2002).

6. Bumanlag, R. G. - "High-solids, aqueous, polymeric dispersions”, U.S. patent no. 5,753,742, (1998). 
7. Calvert, K. O. - "Polymer latices and their applications”. Macmillan Publishing, New York (1982).

8. Dunn, E. R. \& Burroway, G. L. - "Process for increasing the solids content of nitrile rubber latex”, U.S. patent $\mathrm{n}^{\circ} 5,677,368,(1997)$.

9. Dunn, E. R. \& Burroway, G. L. - "Process for increasing the solids content latex", European patent n ${ }^{\circ}$ EP 0814 094 A1, (1997).

10. Force, C. G. - "Process for preparation of high solids concentrated latex”, U.S. patent $\mathrm{n}^{\circ} 4,804,694$, (1989).

11. Freche, P. A. R. \& Muller, P. F. J. - "Process for the production of high solids latex”, U.S. patent no 5,476,897, (1995).

12. Hoy, K. L. \& Peterson, R. H. - "High solids latexes", U.S. patent no 4,130,523, (1978).

13. Lovell, P. A. \& El-Asser, M. S. - "Emulsion polymerization and emulsion polymers”, John Wiley, New York (1997).

14. Mallya, P. - "Carboxylated latex", U.S. patent $\mathrm{n}^{\circ} 4,780,503,(1988)$.
15. Odian, G. - “Principles of polymerization”. John Wiley, New York (1991).

16. Phyllips Petroleum Co. - "Improvements in or relating to process for producing high solids latex”, U.S. patent $\mathrm{n}^{\circ}$ 724,028, (1952).

17. The B. F. Goodrich Company - "Improvements in or relating to method for producing fluid, high-solids latex”, UK patent $\mathrm{n}^{\circ} 758,622$, (1956).

18. Weitzel, H. P. - "Process for preparing polymer dispersions with a high solids content", U.S. patent $\mathrm{n}^{\circ}$ 6,632,869, (2003).

19. Tang, C. \& Chu, F. - "Semicontinuous emulsion polymerization of styrene-butyl acrylate-methacrylic acid with high solid content". Journal of Applied Polymer Science, 82, p.2352 (2001).

20. Do Amaral, M. \& Asua, J. M. - "Synthesis of high solid content latex using alkali-soluble resin as sole surfactant”. Macrolomecular Rapid Communications, 25, p. 1883 (2004).

Enviado: $30 / 05 / 07$

Reenviado: $29 / 11 / 07$

Aceito: $10 / 12 / 07$ 